\title{
Erratum to: Finite-State Markov Chain Models for the Intensity of Nakagami Fading
}

\author{
Michael A. Juang $\cdot$ Michael B. Pursley
}

Published online: 10 August 2013

(C) Springer Science+Business Media New York 2013

Erratum to: Int J Wireless Inf Networks (2013) 20:95-102

DOI 10.1007/s10776-013-0206-8

The Acknowledgment section has been inadvertently omitted in the original publication of this article. The complete text should read as given below.

Acknowledgments The research reported in the article was supported by the Office of Naval Research under Grant N00014-12-10060 .

The online version of the original article can be found under doi: 10.1007/s10776-013-0206-8.

M. A. Juang $(\bowtie) \cdot$ M. B. Pursley

Department of Electrical and Computer Engineering, Clemson

University, 319 Engineering Innovation Building, Clemson,

SC 29634, USA

e-mail: mjuang@clemson.edu

M. B. Pursley

e-mail: pursley@clemson.edu 